\title{
A contribuição dos periódicos científicos para o avanço da ciência e o papel da Revista Educitec
}

landra Maria Weirich da Silva Coelho (D) https://orcid.org/0000-0003-3513-962X

Instituto Federal do Amazonas

E-mail: iandra.coelho@ifam.edu.br

Dadas as circunstâncias adversas em que o mundo se encontra, devido a atual crise da humanidade contemporânea com a pandemia do novo coronavírus (COVID-19), não poderia deixar de iniciar a escrita do Editorial de 2021 da Revista Educitec me solidarizando pelas constantes perdas, especialmente na região norte, que foi assolada no início desse ano, pelo aumento da quantidade de pessoas infectadas com uma nova variante mais transmissível do vírus e pelas mortes, muitas delas causadas pela falta de oxigênio nos hospitais, carência de leitos e vagas em UTIs, assim como escassez de insumos básicos para atendimento à população.

Nesse cenário, perdemos muitos de nossos colegas professores e técnicos, assim como o magnífico reitor de nossa instituição, professor Antônio Venâncio Castelo Branco (in Memorian) e um dos membros do Comitê Editorial Científico da Educitec, professor Dr. Augusto Fachín Terán (in Memorian), da Universidade do Estado do Amazonas, que além de sua atuação na Revista Educitec, também deixou uma larga contribuição, por meio de suas pesquisas e um legado, a partir de sua experiência na área de Ecologia de quelônios Amazônicos e Ensino de Ciências em espaços não formais.

Tais acontecimentos culminaram na dificuldade perceptível em selecionar uma temática para a escrita do Editorial de 2021, devido a uma mescla de sentimentos como a tristeza e a indignação que somados à resiliência e a esperança convergiram para imprimir um trabalho cada vez mais diligente, juntamente com a equipe editorial, para dar continuidade, para seguir adiante e buscar a cada dia potencializar a comunicação científica, sua devida divulgação e lugar de direito no meio acadêmico e na sociedade.

Nesse sentido, esse Editorial é tomado com um lugar de destaque para tratar desses temas, para socializar as novas ações e avanços da Revista, assim como evidenciar a importância da ciência e da divulgação científica, temas que devem fazer parte do nosso repertório, especialmente em um momento histórico que vivenciamos as inovações relacionadas ao desenvolvimento de vacinas que representam um passo vital no enfrentamento à pandemia e seus desafios. 
Apesar dos inúmeros desafios e das constantes indagações sobre a vacina, com relação à falta de respostas sobre sua eficácia, proteção, capacidade de cobertura vacinal, a vacinação continua sendo a principal solução para o agravamento da doença e das mortes e nessa perspectiva o valor da ciência brasileira se reflete nas constantes publicações científicas relacionadas à doença.

A ciência possibilitou esses avanços na área da saúde e suas contribuições são inquestionáveis, impactando a vida de pesquisadores, das instituições e da sociedade. Nesse sentido, "a ciência ganhou mais espaço e com ela a produção do conhecimento, refletida no crescimento da literatura e desenvolvimento de técnicas e especializações de áreas" VALÉRIO; PINHEIRO, 2008, p. 160).

Grande parte destes impactos são efetivados pelas revistas científicas, que têm papel fundamental no processo de comunicar a ciência e a missão de levar esses conhecimentos além, no intuito de potencializar a divulgação dos resultados das investigações e consolidar novas formas de comunicação científica, com fomento ao acesso aberto e mudança de cultura, na produção, revisão e divulgação, e potencial criação de um ambiente favorável à disseminação científica, pautada nos princípios de ética e integridade.

Nesse contexto, "a comunicação científica se tornou vital para a Ciência, pois, além de disseminar os resultados das pesquisas, propicia a proteção da propriedade intelectual pela identificação de seu produtor e consolida o conhecimento por meio da análise e aceitação dos resultados pela comunidade científica" (MIRANDA; CARVALHO, COSTA, 2018, p. 7). Para os autores, "a comunicação difundida por meio de periódicos científicos colabora expressivamente no desenvolvimento da ciência, uma vez que esses são apontados como veículos de comunicação, contribuindo com a rápida divulgação dos resultados e novas metodologias de pesquisa" (MIRANDA; CARVALHO, COSTA, 2018, p. 1)

A difusão da comunicação científica, como meta principal, também traz diferentes desafios aos periódicos científicos e suas equipes editoriais, que envolvem a qualidade do conteúdo e a carência de recursos para manter e potencializar as revistas científicas, no sentido de tornar factível a operacionalização dos fluxos das informações e a eficiência das ações, maior difusão da comunicação científica, e modernização do processo, em razão da rapidez, inovações na apresentação dos conteúdos, ampla visibilidade por meio do acesso livre à informação, agilidade e transparência nos procedimentos editoriais.

Essas ações podem beneficiar autores, pesquisadores, instituições e a comunidade, fomentando uma cultura de convergência e colaboração, no sentido de consolidar um ecossistema que envolva um processo contínuo de pesquisa, produção, publicação, compartilhamento, divulgação, acesso e uso do conhecimento, tendo em vista a disseminação de "informações referentes aos rumos da ciência, transformando os trabalhos publicados tangíveis e acessíveis à discussão perante a comunidade acadêmica" (MIRANDA; CARVALHO; COSTA, 2018, p. 1). 
Essa disseminação de caráter dinâmico transcende a ampla divulgação de resultados das pesquisas em outras áreas, como a de ensino, no caso da Revista Educitec, evidenciando o papel desse periódico na publicação e divulgação de temáticas relacionadas ao desenvolvimento científico e tecnológico nessa área, assim como os avanços, perspectivas, desafios, progressos e tendências no contexto educacional, a fim de ampliar os debates no contexto educativo, gerando impacto acadêmico e social.

Uma das ações refletiu-se na organização de um volume especial dedicado à publicação de artigos sobre a temática dos Desafios e avanços educacionais em tempos da COVID-19, com a colaboração dos professores doutores Juliana MesquitaVidal Martínez de Lucena, do Instituto Federal do Amazonas e Palitha Edirisingha, da Universidade de Leicester. Os artigos abordaram temáticas direcionadas à área de ensino e aprendizagem procedimentos metodológicos adotados, resultados obtidos ou esperados, os impactos das experiências no processo de ensino e aprendizagem, perspectivas de abordagem didática em áreas específicas, revisões sistemáticas da literatura sobre metodologias de ensino, entre outras propostas.

Por meio de uma nuvem de palavras, evidencio algumas das temáticas abordadas nessa edição, que objetivou proporcionar novas discussões e estratégias para reconfiguração do espaço escolar e do processo de aprendizagem no atual momento e que podem contribuir para novas reflexões e tomada de decisão de um planejamento escolar em diferentes âmbitos local, regional e nacional. A Figura 1 apresenta uma demonstração visual, de acordo com a frequência de ocorrência das palavras dos artigos publicados nesta edição especial.

Figura 1. Visão geral das palavras mais frequentes na seção sobre COVID-19

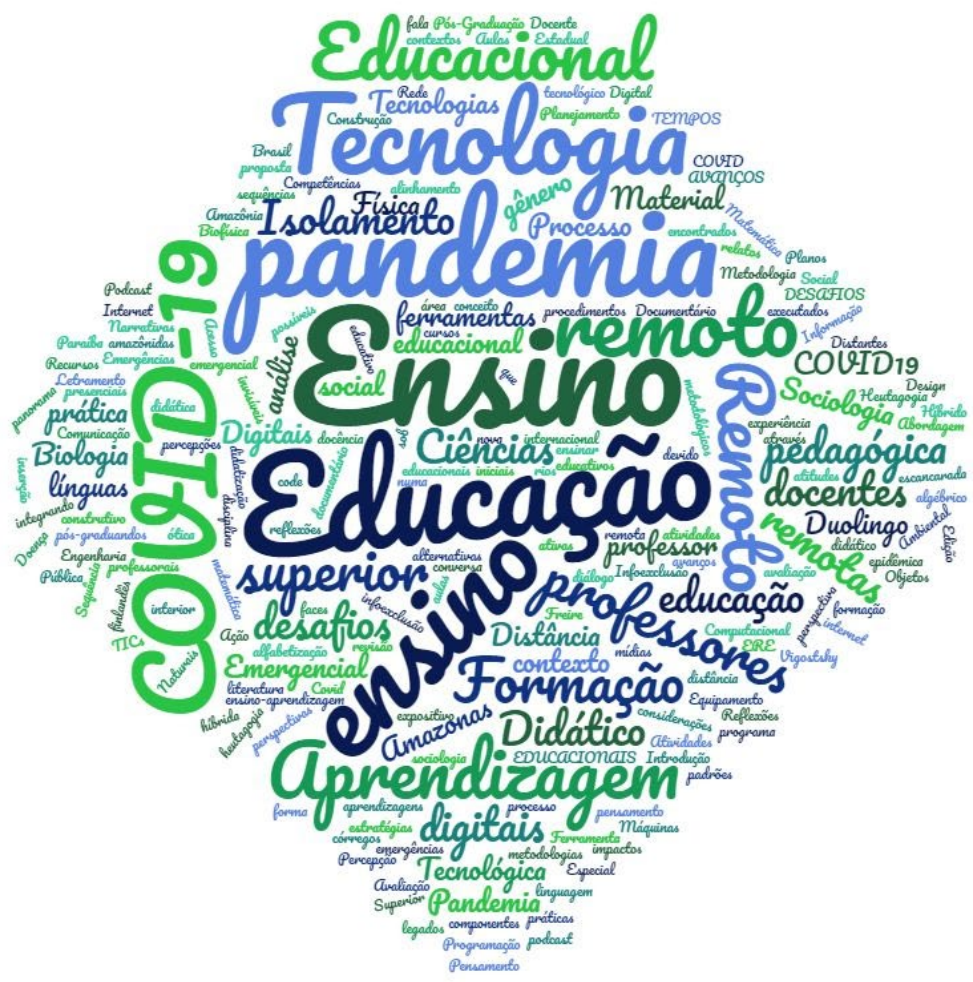


Com esse compromisso científico e social, a equipe Educitec espera que os conhecimentos que estão sendo divulgados sejam úteis e possam contribuir para a comunidade acadêmica e a sociedade em geral. Para tanto, busca-se refletir constantemente sobre o fluxo de produção, disseminação e difusão da comunicação científica, a fim de imprimir as melhorias necessárias.

Face a esse propósito, na atual complexidade contemporânea, a revista segue o caminho buscando o aperfeiçoamento na editoração, fomento à internacionalização da produção científica, atualização das políticas editoriais e um planejamento de ações a curto, médio e longo prazo, embasadas na permanente reflexão e sistematização dos processos, visando dinamizar o gerenciamento técnico, científico e tecnológico do processo da produção editorial da Educitec, por meio da identificação dos obstáculos, com a missão de oferecer conhecimentos novos e relevantes dentro de diferentes áreas temáticas, pautado no elevado processo de seleção editorial segundo padrões éticos e de integridade (TRZESNIAK, 2009).

Esse caminho leva em conta a quebra de paradigmas para a comunicação científica, tendo como base o movimento da Ciência Aberta, do acesso aberto à literatura científica, da leitura e reutilização sob licenças Creative Commons em que as restrições de direitos autorais e licenças de uso deixam de existir. Nesse sentido, a revista Educitec passou a adotar mais alguns parâmetros com atualização das políticas editoriais voltadas para ética e a integridade nas publicações científicas, no sentido de consolidar novos espaços formativos para o desenvolvimento e implantação de uma conduta responsável em pesquisa na comunidade científica, voltada para o fomento da difusão on-line de artigos, por meio de iniciativas e boas práticas visando tornar a pesquisa e sua divulgação aberta e acessível nas diferentes fases de desenvolvimento, com foco em oportunidades de colaboração entre os pesquisadores.

Entre as novas práticas citam-se também a adoção do código de boas práticas para editores, que consolida o compromisso da Revista Educitec com seus leitores e demais colaboradores (pareceristas, autores), potencializando uma conduta editorial pautada, especialmente nos princípios internacionais do Códigos de Ética do Committee on Publication Ethics (COPE), a indicação dos papéis de cada um dos autores na produção científica em manuscritos de autoria múltipla, com informações sobre as contribuições desempenhadas por cada autor, (com base em 14 funções da Taxonomia de Funções do Colaborador - Contributor Roles Taxonomy/CRediT) e a construção de um plano de marketing para divulgação dos trabalhos publicados.

Finalizo esse editorial, reavivando meu sentimento de esperança em detrimento da impotência, e apesar de tantos desalentos, enquanto a doença avança significativamente outros estados do país, rogo pela garantia de uma cobertura vacinal urgente para auxiliar no tratamento dessa crise sanitária que assola a humanidade, políticas públicas adequadas, presença e desenvolvimento potencial das pesquisas e pelo progresso de uma ciência brasileira humanista com potencial processo civilizatório. Para isso, continuaremos trabalhando constantemente para imprimir a qualidade que a ciência merece e garantir a manutenção de nossos periódicos científicos, 
para ampla disseminação e consolidação de novas formas de apropriação do conhecimento.

landra Maria Weirich da Silva Coelho

Editora

\section{Referências}

MIRANDA; A. C. C.; CARVALHO, E. M. R.; COSTA, M. I. O impacto dos periódicos na comunicação científica. Biblos: Revista do Instituto de

Ciências Humanas e da Informação, v. 32, n. 1, p. 01-22, jan./jun. 2018.

Disponível em: https://periodicos.furg.br/biblos/article/view/7177. Acesso em:

12 jan. 2021.

TRZESNIAK, P. A estrutura editorial de um periódico científico. In: SABADINI, A. A. Z. P.; Sampaio, M. I. C.; Koller, S. H.: Publicar em Psicologia: um enfoque para a revista científica. São Paulo/SP: Associação Brasileira de Editores Científicos de Psicologia e Instituto de Psicologia da Universidade de São Paulo. Disponível em: http://www.publicarempsicologia.blogspot.com. Acesso em: 12 jan. 2021.

VALÉRIO, P. M.; PINHEIRO, L. V. R. Da comunicação científica à divulgação. Transinformação, Campinas, v. 20, n. 2, p. 159-169. 2008. Disponível em:https://www.scielo.br/scielo.php?pid=S010337862008000200004\&script=sci_abstract\&tIng=pt. Acesso em: 2 fev. 2021.

Recebido: $17 / 03 / 2021$

Aprovado: $17 / 03 / 2021$

Como citar: COELHO, I. M. W. S. A contribuição dos periódicos científicos para o avanço da ciência e o papel da Revista Educitec. Revista de Estudos e Pesquisas sobre Ensino Tecnológico (EDUCITEC), v. 7, e168621, 2021.

Contribuição de autoria:

landra Maria Weirich - Escrita (rascunho original) e Escrita (revisão e edição).

Direito autoral: Este artigo está licenciado sob os termos da Licença Creative CommonsAtribuição 4.0 Internacional.

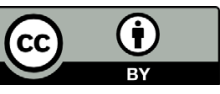

